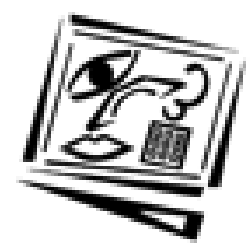

\title{
The Titanic, Volkswagens and collaborative group work: Remaking old favourites with new learning technologies
}

\author{
Colin Baskin \\ James Cook University
}

Unsinkable ships, Volkswagens and collaborative group work have much in common. They have each undergone a recent revival of sorts; in each case the new version bears a strong Wittgensteinian resemblance to its more classic predecessor; and in each case the end user is able to enjoy the nostalgic experience of having once again rediscovered the wheel. This is a powerful experiential principle, one so powerful in fact that it drives us to part with the cost of a movie ticket even though we know how the movie ends! The ship still sinks on April 14th; the 'bug' still looks like a beetleplus and group work is still largely a 'lottery' experience for students at university.

This paper is about finding a way (or ways) to disrupt this cycle of repetition, not by raising the Titanic (for this has been tried), nor by terminating the Volkswagen (Woody Allen pointed out in the film Sleepers that they were clearly unstoppable). Rather, this paper will concentrate on how to re-engineer collaborative group work practices using online learning technologies, thereby enhancing their role as an effective, flexible and efficient learning exchange. In comparing the performance outcomes of 'online' learning groups to a study of 'real time' learning groups (Hogan 1999), the paper sets about building a case for the former. The paper deals specifically with how collaborative online learning groups can be used to:

- Establish an authentic learning context

- Accommodate learner needs

- Enrich learner experiences; and

- Inform instructor perspectives. 


\section{Why group processes?}

Understanding small group formation, its dynamics, processes and outputs are foundational elements in the provision of effective learning environments (Hogan, 1999). Let's begin by extrapolating some of the common ground underlying our use of groups as a learning technology. For the benefits of efficiency and productivity, groups accomplish tasks that can not be done by individuals alone; they bring multiple perspectives to bear on a single problem; they capture the dynamic of real world complexity; they provide a vehicle for decision making and taking, and they impose an efficient means of organisational control over individual behaviours. For socialisation purposes, groups form a key element in the broader social system. They are instrumental in the formation of personality; are agents of both socialisation and control, and act as a motivational tool within a continuous cycle of learning.

Yet group work from the practitioner point of view can break down for a variety of reasons, many of which relate directly to student group skill processes. The particular group skills featured in this discussion include those germane to undergraduate business programs (Hogan, 1999; Baskin \& Greenfield, 1999), and include:

- The stages of group development (Tuckman \& Jensen, 1977)

- Team roles (Belbin, 1981)

- Conflict resolution (Dick, 1986); and

- Giving and receiving feedback (Hopson \& Scally, 1982).

\section{New ways of 'group' learning}

At the institutional level, the use of group work as a learning technology has mapped onto wider debates about more institutional notions of 'learning'. In higher education, learning has become a consumer durable, and is often taken to mean the transformation of existing and known information into new configurations, so much so that contemporary changes to society and to patterns of social participation are framing new constructions and meanings of 'learning' (Mezirow, 1996; Senge, 1990). Learning has become a key interface for processing the acceptance of new values through change processes. At the university level this is captured in a range of terms designed to convey the dynamic of the new learning agendas: 'action learning', 'collaborative learning', 'lifelong learning', 'self paced learning', 'situated learning', 'distributed learning' and more recently 'flexible learning'. In moving towards what Lemke (1996) terms 
the 'interactive learning paradigm', higher education has adopted two key principles consistent with group learning technologies:

- namely that learning is always mediated by and occurs through language (Falk, 1997; Gee, 1997); and that

- learning is distributed across a range of other people, sites, objects, technologies and time (Gee, 1997).

The corollary of these positions is a movement towards a form of learning that is instant and constant, yet still traceable to discernible group skills and practices (Falk, 1997). Field (1995:151) identifies six aspects that define contemporary learning.

- Learning takes place amidst continuous environmental turbulence

- Knowledge is the primary source of learning exchange

- Learning is multi-dimensional

- Traditional knowledge boundaries are now fuzzy and more permeable

- Decision making is characterised by reduced system time frames; and

- Internationalisation is the prime catalyst for changing practice.

Falk (1997:54) draws attention to four recurring themes in Fields' (1995) analysis, these being an emphasis on communication, a focus on knowledge, the need for an adjustment process to embrace and implement new values, and the flexible assembly of work ready skills and competencies. In the context of university learning, online group processes can be viewed functionally as learning. Both Field (1995) and Falk (1997) point to a need to embed new ways of learning in an experiential model, wherein knowledge is a product of the transformation of student learning experiences (Kolb 1984).

\section{Online learning groups: An authentic group work 'experience'}

In an experiential model, the learner transforms not only learning attitudes and behaviours, but also issues of environment, context, experience, performance and reference (Marsick,1987). Lankshear (1997) suggests that 'new' learning system stressors are most likely to occur around the increased use of new technologies. Hence, experiential learning will by definition need to reflect changes occurring in industry and commerce globally, and incorporate new digital literacies and languages of technology. Increasingly complex micro-worlds are in this way replaced by increasingly complex learning environments. Online group work 
therefore presents a formidable content, knowledge and curriculum challenge for university teaching staff.

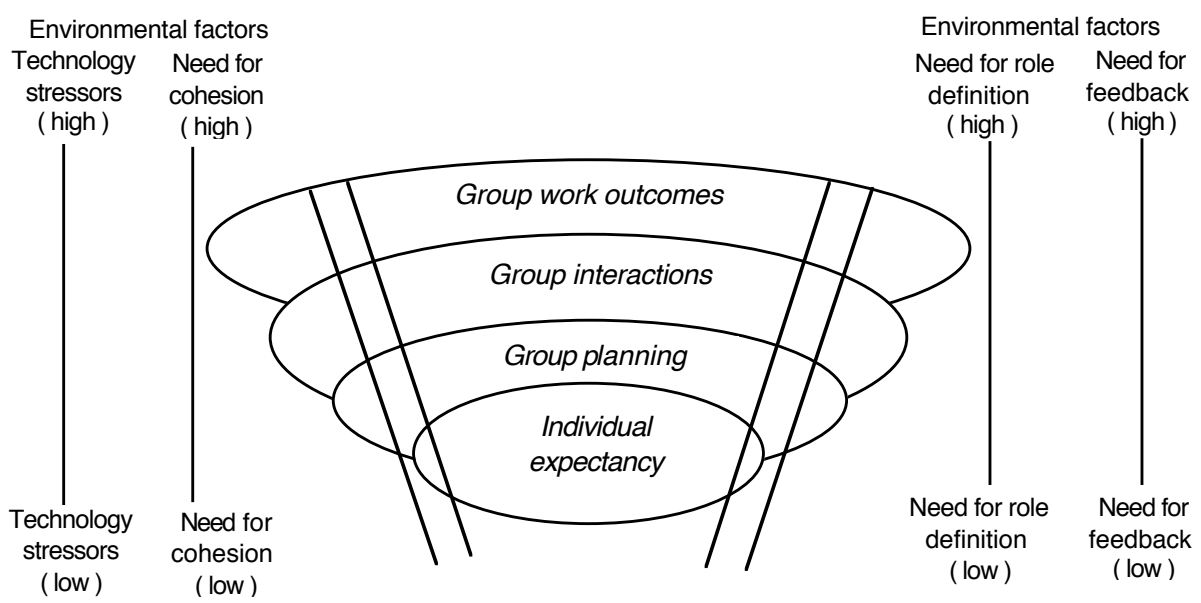

Figure 1: Group Learning Systems Model (adapted from Suchan \& Dulek, 1998)

The group learning system model (Figure one) underlying this project presents learning as a multi-directional, dynamically negotiated, multiply influenced process that occurs within and across groups of learners. In this 'experiential learning cycle', group processes transform learner planning, interactions, assessment methods as well as individual expectancies. The increasing complexity of online group learning is reflected (Figure 1) in the increasing size and scope of student activities, starting from individual efficacy and culminating in full immersion of the student in online group assessment. Corresponding changes in the learning environment are also dynamically captured in the model, reflecting how needs for time, process and group skills management change as a dynamic of group work. Group work is captured as a dynamically negotiated learning process, rather than a one way dynamic located in the individual. It necessitates 'authentic' interaction between learners and a learning event that works to transform both, promoting learning within the nexus of 'activity, tool and culture' (Figure 2 below). In this light not only do students learn, they also become critically aware of learning contexts, capabilities, cultures and tools (Kolb, 1984). Hogan (1999) highlights the potency of semi-autonomous study groups in her benchmark study of real time group work in Curtin University's undergraduate School of Management. This paper adopts and 
translates her methodology to examine how online technology impacts on group learning activities.

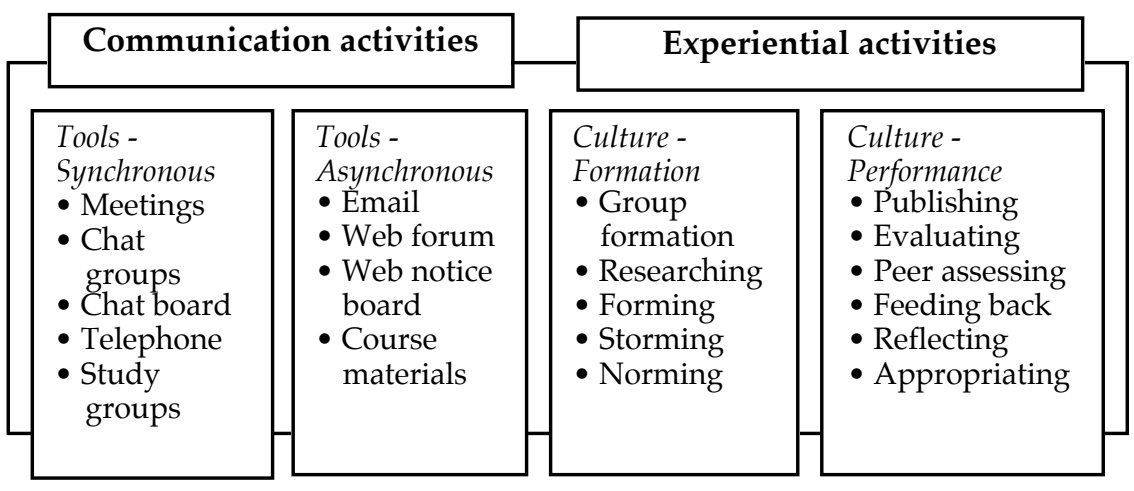

Figure 2: Critical activities in online group work

\section{Establishing an authentic learning context}

The host subject for this study was, like that of the Hogan (1999) project also an undergraduate management subject. A feature of the host subject was it's 'virtual' environment, utilising GroupWare to establish online learning groups (numbering six students) in week one of the program. Learning group activities featured student collaborations in solving situated problems related to course assessment items. Online meetings consisted of sharing information, dissecting course materials, collecting project data, collating project data, interpreting data, as well as publishing results from fieldwork projects.

Traditional pedagogical approaches to group learning often tend to be hybrid in their nature. They are often implicitly framed by one culture (in most cases the classroom), but are explicitly attributed to others (industry, commerce, quality and management agendas amongst others). Many of the group activities students complete are simply not the authentic activities of practitioners, and would not be endorsed by nor make sense to the 'business' culture to which they are attributed. Online group work can overcome this limitation.

Group work in an online environment replicates a process management framework. Critical links to learning about group processes are made more transparent in an online environment. They are directly situated to 
stimulate a reflective cycle amongst group members. Asynchronous and synchronous interactions provide extended opportunities for developing and exchanging ideas, and for developing and appropriating 'learning' through conversation and narrative. Peripheral participation is a feature of the online environment, where those who adopt a passive role within group exchanges can still learn a great deal from a legitimate position on the periphery. Kolb's (1984) experiential cycle is useful here, conferring that the important discourse in learning is not always 'declarative and direct'. The experiential cycle supports those who enter the 'learning' of the group for the first time by providing access to the distributed knowledge of its members. Students benefit from exposure to learning opportunities that enable them to observe how others authentically behave, act and perform. These practices seem closer to the more familiar organisational practices of mentoring, modelling and process management. In short, the online group task required students to work in collaborative study groups for two purposes:

- To post an electronic discussion paper onto the electronic subject forum, and to peer review and assess the papers of each learning group member; and:

- To undertake a semester long collaborative fieldwork project.

This continuous group learning cycle stimulated a climate of exchange, promoted learning to learn through materials, activities, modelling of behaviour, self reflection and assessment; involved learners in realistic challenges, and created the context for building conversations between disciplines, experiences, ideas, literature and electronic media (Baskin, 1999). In this way, the classroom was extended far beyond the physical and timetabled dimensions of the subject.

An evaluation of student perceptions of online group learning was conducted, returning 136 valid responses from a sample of 141 students. This evaluation process was a replication study based on a similar project (Hogan, 1999), but differed in so far as the current project featured online learning groups, whereas the comparative project (Hogan, 1999) featured 'real time' learning groups. The purpose of the summative evaluation was to capture and bracket student accounts of group learning in an online environment, a summary of which is provided (Table 1). All respondents were new to online group work. A total of 115 students also responded to the open ended prompt "what do you believe you got out of participating in your online learning group?" 
Table 1: Summary statistics - Student perspectives online learning

\begin{tabular}{|c|c|c|c|c|c|c|}
\hline \multirow[b]{2}{*}{ Individual perspective } & \multicolumn{2}{|c|}{ Agree } & \multicolumn{2}{|c|}{ Disagree } & \multicolumn{2}{|c|}{ Unsure/DK } \\
\hline & No. & $\%$ & No. & $\%$ & No. & $\%$ \\
\hline Learnt more about myself & 82 & 60.3 & 21 & 15.4 & 33 & 24.3 \\
\hline Made new friends & 108 & 79.5 & 15 & 11.1 & 13 & 9.6 \\
\hline Learnt more about old friends & 59 & 43.4 & 26 & 26.4 & 41 & 30.1 \\
\hline Felt at risk at first & 59 & 43.4 & 45 & 33.1 & 30 & 22.1 \\
\hline Learnt to speak up in a group & 75 & 55.1 & 30 & 22.1 & 30 & 22.1 \\
\hline $\begin{array}{l}\text { Can remember experiential exercises more } \\
\text { easily }\end{array}$ & 60 & 44.1 & 15 & 11.0 & 60 & 44.1 \\
\hline $\begin{array}{l}\text { Learnt to further develop trust in other } \\
\text { students }\end{array}$ & 82 & 60.3 & 21 & 15.5 & 31 & 22.8 \\
\hline Learnt to facilitate a group & 103 & 75.7 & 15 & 11.0 & 18 & 13.2 \\
\hline I took responsibility for my own learning & 122 & 89.8 & 6 & 4.4 & 8 & 5.9 \\
\hline $\begin{array}{l}\text { Relate organisational behaviour theories to } \\
\text { real world }\end{array}$ & 107 & 78.7 & 14 & 10.3 & 15 & 11.0 \\
\hline I felt qualified to give feedback & 93 & 68.4 & 22 & 16.1 & 21 & 15.4 \\
\hline I felt the feedback received was adequate & 93 & 68.4 & 18 & 13.3 & 24 & 17.6 \\
\hline \multicolumn{7}{|l|}{ Group perspective } \\
\hline $\begin{array}{l}\text { Learnt about people I wouldn't normally } \\
\text { be exposed to }\end{array}$ & 97 & 71.3 & 12 & 8.8 & 27 & 19.9 \\
\hline Learnt about group behaviour & 112 & 82.4 & 7 & 5.2 & 17 & 12.5 \\
\hline Mixed students from different cultures & 78 & 57.3 & 36 & 26.4 & 22 & 16.2 \\
\hline Showed up immature students & 50 & 36.8 & 26 & 26.4 & 49 & 36.0 \\
\hline Watched power struggles & 58 & 42.7 & 33 & 31.6 & 35 & 25.7 \\
\hline Saw how my behaviour affects others & 88 & 64.7 & 16 & 11.7 & 31 & 22.8 \\
\hline Mixed students of different age groups & 106 & 77.9 & 13 & 9.6 & 16 & 11.8 \\
\hline $\begin{array}{l}\text { Confront people exhibiting dysfunctional } \\
\text { behaviour }\end{array}$ & 34 & 25.0 & 52 & 38.2 & 50 & 36.8 \\
\hline Fun & 88 & 64.7 & 22 & 16.2 & 26 & 19.1 \\
\hline Chance to observe different personalities & 117 & 86.0 & 7 & 5.2 & 12 & 8.8 \\
\hline Gave me experience in conflict & 76 & 55.9 & 25 & 18.4 & 34 & 25.0 \\
\hline $\begin{array}{l}\text { Deal with people with dominating } \\
\text { personalities }\end{array}$ & 85 & 62.5 & 26 & 19.1 & 25 & 18.4 \\
\hline $\begin{array}{l}\text { Others took responsibility for their own } \\
\text { learning }\end{array}$ & 96 & 70.6 & 13 & 9.5 & 27 & 19.9 \\
\hline Learnt to include quiet people & 93 & 68.4 & 12 & 8.8 & 30 & 22.1 \\
\hline \multicolumn{7}{|l|}{ The project } \\
\hline Unorthodox/unusual way of learning & 71 & 52.2 & 33 & 24.2 & 31 & 22.8 \\
\hline Learnt to be task orientated & 102 & 75.0 & 8 & 5.8 & 26 & 19.1 \\
\hline Learnt to manage myself & 110 & 80.9 & 13 & 9.6 & 13 & 9.6 \\
\hline Learnt to manage ourselves & 93 & 68.4 & 18 & 13.3 & 25 & 18.4 \\
\hline Gave me experience in planning & 106 & 78.0 & 10 & 7.3 & 20 & 14.7 \\
\hline Gave me experience in time management & 106 & 78.0 & 10 & 7.3 & 20 & 14.7 \\
\hline
\end{tabular}




\section{Accommodating learner needs: Student impressions}

The tabled results (Table 1) indicate that students endorse online peer review as an appropriate forum for assessment. The table indicates a high level of acceptance of responsibility for self directed learning (89.8\%), and self management $(80.9 \%)$ respectively. Student's comments on these issues included:

I relish the opportunity to conduct my own learning and put the responsibility on myself.

The project created responsibility to my group and myself.

The students also report positively on their learning about aspects of group behaviour $(82.4 \%)$ and the challenge of group facilitation $(75.7 \%)$. Emphasis on aspects of member participation indicate an increased awareness of how 'my behaviour effects others' $(64.4 \%)$, experience with hands on conflict management $(55.9 \%)$, managing group processes to include 'quiet' people $(69.9 \%)$, and in dealing with the dominant personality $(61.6 \%)$. The online environment was clearly able to stimulate a broad range of 'authentic' group and interpersonal challenges for learners.

\section{Enriching learner experiences}

The formation of 'new learning networks' was also a feature of student responses. Some $80 \%$ of respondents made new friends, $78 \%$ engaged in cross-age learning groups, and $86 \%$ of students reported the opportunity to observe 'different personalities'. The online nature of respondent comments in this dimension reflect the following:

I gained more confidence in working in groups.

The group interaction was definitely 1 "for me. My group was made of people that didn't know each other, our broad diversities brought a lot of knowledge to the activity, it was good.

I ended up a better team member, learnt how to work in groups with different people.

It gave me a new knowledge on what others really thought of my work. I did make new friends..

I found that although this assignment was confronting (through peer assessment), I thought it was quite productive in helping us learn about ... ourselves.

I feel that the method used was very important and rewarding. We found a need for others! 
Students saw the online method of group work and assessment as somewhat 'unorthodox' $(52 \%)$, and nearly half informants declared that they felt at risk 'at first' $(43 \%)$. Yet corresponding attributions of better self management $(81 \%)$, and more meaningful engagement with others 'I wouldn't normally be exposed to $(71 \%)$ indicates that students relied on group behavioural theories and models $(82 \%)$ to build dialogue between theory and practice in a real world setting (79\%). Results captured in Table 1 tend to suggest that collaborative learning groups, and peer assessment processes, provide a translational learning model that is able to situate students within contemporary organisational learning systems.

\section{Informing instructor perspectives}

The thirty-two variables presented in Table 1 were collapsed into related categories, and were entered into a hierarchical cluster analysis for purposes of dimension reduction. The cluster analysis was used to examine relationships between related groups of variables, and provided valuable information about the 'hierarchy' of skills and practices students attribute to effective online group work (Figure 3).

Figure 3: Skills and practices for effective online group work

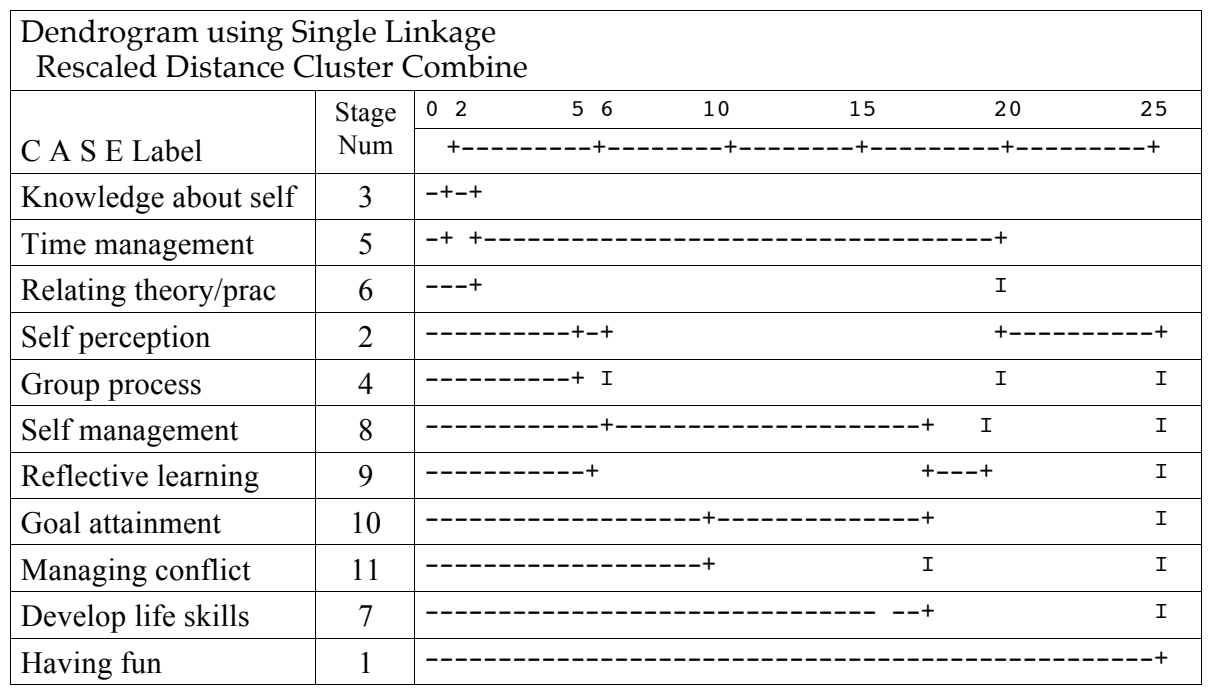

Read from left to right, the hierarchical clustering at stage 2 highlights that students attribute increased importance to self knowledge and time management in an online group work setting. Collaborative learning and peer assessment processes situate the student within an 'experiential cycle' 
of learning, and facilitate the translation of 'group' theory to the level of 'personal' and appropriated practice. The second (stage 6) cluster captures the dynamics of group formation. Students report increased awareness of themselves as group members (self perception), their need to align personal norms and behaviours (group processes), their need to respond to feedback (self management), and how this dynamic of learning confronts their existing (concrete) experiences of themselves as learners (reflective learning). These outcomes clearly map the learning outcomes of the subject.

The third cluster forms at stage ten (10). Here goal attainment shows that online group work necessarily involves a strategic element, is 'outcomes oriented', and that group outcomes often depend on managing conflict while developing more transferable 'life skills' through group work. The fourth cluster to emerge is an isolate, and provides an interesting footnote to online group work. That 'fun' remained an isolated cluster is indicative of its status as an afterthought. Naturally as teachers we prefer to think that learning is fun, but as one respondent concludes:

I suppose it was fun now that it's over... (hmm).

\section{Conclusion: Does online group work 'measure up' as a remake?}

This paper has presented the view that a rich online learning environment creates and invents opportunities for rich learning experiences. It also facilitates curriculum planning, by providing an effective frame for the teaching of group development theories (Tuckman \& Jensen, 1977), team roles (Belbin, 1981), conflict resolution skills (Dick, 1986) and the giving and receiving of feedback (Hopson \& Scally, 1982). But how does online group work compare against its real time counterpart? For this comparison, the paper turns to a parallel study (Hogan, 1999).

The dimensions presented for comparison in Table 2 are those dimensions where online and real time (Hogan 1999) group outcomes differ. The key issue here is not whether one mode of group work outperforms the other, but rather how each model of collaborative group work enhances specific teaching and learning outcomes. 
Table 2: Comparison of real time and online group learning outcomes (Hogan 1999)

\begin{tabular}{|l|c|c|}
\hline Student perspectives & $\begin{array}{c}\text { Online } \\
\text { environ. } \\
\text { Respondent } \\
\text { agreement } \%\end{array}$ & $\begin{array}{c}\text { Real time } \\
\text { setting } \\
\text { Respondent } \\
\text { agreement } \%\end{array}$ \\
\hline Learnt more about myself & 60 & $<75$ \\
\hline Made new friends & 80 & $<95$ \\
\hline Felt at risk at first & 43 & $<61$ \\
\hline Learnt to speak up in a group & 55 & $<75$ \\
\hline Can remember experiential exercises more easily & 44 & $<67$ \\
\hline Learnt to facilitate a group & 76 & $<83$ \\
\hline I took responsibility for my own learning & 90 & $>80$ \\
\hline Relate organisational behaviour theories to real world & 79 & $>61$ \\
\hline Learnt about people I wouldn't normally be exposed to & 71 & $<79$ \\
\hline Watched power struggles & 43 & $>32$ \\
\hline Mixed with students of different age groups & 78 & $<99$ \\
\hline Confront people exhibiting dysfunctional behaviour & 25 & $<34$ \\
\hline Fun & 65 & $<99$ \\
\hline Deal with people with dominating personalities & 63 & $<99$ \\
\hline Others took responsibility for their own learning & 71 & $>65$ \\
\hline Learnt to include quiet people & 68 & $<99$ \\
\hline Unorthodox/ unusual way of learning & 52 & $<73$ \\
\hline Learnt to manage myself & 81 & $>72$ \\
\hline Gave me experience in time management & 78 & $>68$ \\
\hline
\end{tabular}

A further important distinction is the degree to which group work is taken out of the embedding world, to become something more to 'learn about' rather than something that is 'useful in learning'. As a socialising agent, the real time group work engages students at a range of levels in 'learning about groups'. This immersion into real time groups presents frequent authentic opportunities for learning about the self, for making new and different friends, feeling at risk, developing assertiveness, facilitating group processes and relating to experiential group exercises. The essentialist nature of learning in the real time group setting is about learning how to become a group member. Where this learning is successfully transferred, high levels of student response indicate that real time group work is a fun, albeit an unorthodox method of experiential learning (Hogan, 1999). 
Online group work on the other hand defines itself as a more clinical and less volatile learning environment. Its terrain is less cluttered with interpersonal issues. Its culture promotes an increased sense of responsibility for learning, for self and time management as a learner, and is able to more successfully translate organisational behaviour theories to the real world context of the learner. This is not to suggest that 'messy' interpersonal dramas are not part of the online group environment, for the online environment is still punctuated by conflict, member dysfunction, dominant personalities, quiet lurkers, power struggles and accountability. Rather, this paper suggests that the online environment is simply less extreme in its representations of such 'real world' behaviours. It also suggests that evidence of these behaviours is more transparent online. The online environment is well placed to 'model' group processes as 'something useful in learning', rather than something discrete that needs 'to be learned'.

To many, this is a matter of simply splitting hairs, yet it is also for this reason that group work has long suffered as a result of inadequate epistemology. Group work provides learning opportunities that are distributed across a range of other people, sites, technologies, objects and time (Gee, 1997). Online group work directs learning practices and cultural expectations to interact and extend each other. Students experience the legitimacy of their implicit knowledge and its availability as scaffolding in apparently unfamiliar tasks and settings. Learning how to make groups 'something useful in learning' transcends the need to learn about 'becoming a group member'. At this point, students no longer behave like students but as practitioners within the context of their own complex learning environment. Data presented here confirms a strong sense of the student ownership of learning in the online group work setting.

Despite this a simple caveat remains: While we as tertiary teachers continue to conscript learners to work in groups, we need also to be aware that we may well be setting up a series of experiences that discourage students from seeking team involvement beyond the context of our particular subjects. In an online group work environment, the margin for error increases. The instructor manipulates not only content, pedagogical, personal and institutional variables, but adds to these variations in learning time, medium and place. Old favourites can be the first casualty in the search for new approaches. Have you ever held your knees to your chin in the back seat of a 'bug', or perhaps resisted the urge to stand on the bow of a boat (any boat) just in case it hits something (anything)? Perhaps then, it is no surprise to learn that old favourites can provide the 'wrong' learning transfer if not carefully and prudently designed. 


\section{References}

Baskin, C. (1999). Flexible Learning - Adding Value to Management Ed. FlexED, $4(3)$.

Baskin, C. \& Greenfield, G. (1999). Learning to manage and managing to learn: Collaborative learning and peer assessment as student practice. Proceedings: Organisations Looking Ahead. School of Management. Griffith University. Brisbane. pp29-37.

Belbin, R. M. (1981). Management Teams - Why They Succeed or Fail. Heinemann: London.

Dick, B. (1986). Applying communication skills to conflict resolution. Learning to Communicate. University of Queensland: Brisbane.

Field, L. (1995). Organisational Learning: Basic Concepts. Understanding Adult Education and Training. Allen and Unwin: Sydney.

Falk, I. (1997). Collaborative learning: Co-constructed meaning mediated by language. Critical Forum, 5(1 \& 2), Adult Literacy and Basic Skills Coalition. Springwood. pp52-70.

Gee, J. P. (1997). Beyond Culture: Communities of practice in the new capitalism. Critical Forum, 5(1 \& 2). Adult Literacy and Basic Skills Coalition. Springwood. pp70-83.

Hogan, C. (1999). Semi-autonomous study groups. International Journal of Educational Management. 13(1), 31-44. MCB University Press: Manchester.

Hopson, B. and Scally, M. (1982). Lifeskills Teaching Programmes No. 2. Lifeskills Associates: Leeds.

Kolb, D. (1984). Experiential Learning. Prentice Hall: Englewood Cliffs, New Jersey.

Lankshear, C. (1997). Digital Rhetorics: Literacies and Technologies in Education Current Practices and Future Directions. Executive Summary. DEETYA, AGPS: Canberra.

Lemke, J. (1996). Metamedia literacy: Transforming meanings and media. In D. Reinking (Ed), Literacy for the 21st Century: Technological Transformation in a Posttypographical World. Erlbaum. New York.

Marsick, V. J. (1987). Learning in the Workplace. Croom Helm: London.

Mezirow, J. (1981). A critical theory of adult education and learning. Adult Education. 32(1), 3-24. 
Senge, P. (1990). The Fifth Discipline: The Art and Practice of the Learning Organisation. Doubleday/Currency: New York.

Suchan, J. \& Dulek, R. (1998). From text to context: An open systems approach to research in written communication. Journal of Business Communication, 35(1), 98108.

Taylor, P. \& Collier, B. (1999). Group Work for Flexible Learning. Griffith Institute for Higher Education. Griffith University. Brisbane.

Tuckman, B. \& Jensen, N. (1977). Stages of Small Group Development Revisited, Group and Organisational Studies. 12, 419-421.

Dr Colin Baskin, Teaching and Learning Development, Cairns Campus, James Cook University. Email: Colin.Baskin@jcu.edu.au 